\title{
Protestantes alemães em Minas Gerais e no Rio de Janeiro: a importância do modelo de aculturação para a história da imigração
}

\author{
German Protestants in Minas Gerais and Rio de Janeiro: the importance of the \\ acculturation model for the history of immigration
}

Protestantes alemanes en Minas Gerais y en Rio de Janeiro: la importancia del modelo de la aculturación para la historia de la inmigración

Roland Spliesgart ${ }^{*}$

\section{Resumo}

A história dos protestantes alemães no Brasil é tratada normalmente por dois pontos de vista: pela formação de igreja ou pelo seu germanismo. Muitas dessas comunidades são caracterizadas na literatura como abrasileiradas. Esse é o caso principalmente no Brasil Central, ou seja, nos estados de Minas Gerais e Rio de Janeiro. A minha abordagem toma como ponto de partida o conceito pejorativo de abrasileirização, para pesquisar os processos de interação e transformação que ele expressa. Na perspectiva teórica, o conceito de aculturação da Antropologia Social pode ser aplicado de forma produtiva para o trabalho histórico. Sob aculturação são compreendidos todos os fenômenos de modificação cultural, que se resultam do contato entre dois grupos de diferentes culturas originárias. Na pesquisa dos migrantes protestantes de origem alemã puderam ser identificados dois fatores que acentuaram a aculturação: por um lado a decisão de emigrar e a crise resultada disso, por outro lado, as condições políticas na Alemanha e no Brasil. Especialmente no campo da religião podem ser demonstrados vários fenômenos, que comprovam a aculturação dos protestants no Brasil.

Palavras-chave: Imigração. Protestantismo. Aculturação.

\begin{abstract}
Graduação em Teologia. Doutor em Ciências Políticas e Econômicas (Universidade de Bremen). Pós-Doutorado (Habilitation) em Teologia (Universidade de Munique). Desde 2004, atua como "Privatdozent" (livre-docente) no Instituto de História da Igreja (História do Cristianismo Global) da Faculdade de Teologia Evangélica da Ludwig-Maximilians-Universität München. O presente artigo baseia-se em uma aula e é resultado de discussões de um minicurso realizado no PPGH na Unisinos de 19/08 a 22/08/2013, como professor visitante do exterior, com apoio financeiro da Capes. Texto e citações traduzidas do alemão para o português pelo próprio autor.
\end{abstract}

Recebido em 28/03/2013 Aprovado em 20/04/2013 http://dx.doi.org/10.5335/hdtv.14n.1.4167 
Com esse texto, pretendo apresentar alguns resultados da minha tese de pós-doutorado sobre os "protestantes alemães em Minas Gerais e no Rio de Janeiro no Império Colonial brasileiro", sob o título "Verbrasilianerung und Akkulturation" (Abrasileirização e aculturação) (SPLIESGART, 2006a). Ela se insere na linha de pesquisa da "História global do Cristianismo", da Faculdade de Teologia Evangélica da Universidade de Munique, que visa a superar o eurocentrismo na medida em que a história dos cristãos não é observada e analisada a partir dos centros ocidentais, mas sim a partir da sua própria dinâmica. Nessa perspectiva, surgiu a questão da "abrasileirização" (Verbrasilianerung), a qual foi inspirada na teoria da aculturação. Com essa minha contribuição, pretendo mostrar, nos exemplos das mencionadas comunidades, a importância do modelo de aculturação para a história de imigração.

\section{A Historiografia dos Séculos XIX eXX}

Todos os trabalhos, nos séculos XIX e $X X$, que tratam da história dos protestantes de origem alemã orientam-se por dois tipos de problematizações: um referente ao surgimento de uma estrutura eclesiástica evangélica no Brasil, na maioria das vezes luterana, e outro lado vinculado à questão da germanidade dos migrantes protestantes. Ambas as perguntas são interligadas, pois, para todos os autores, está claro o fato de que a igreja evangélica alemã continua sendo a "norma" da história dos descendentes alemães. Toda a historiografia é impregnada de uma perspectiva etnocêntrica, que às vezes chega a ser puro racismo.
Martin Dreher fez uma reavalização, em 1975, na sua dissertação Kirche und Deutschtum in der Entwicklung der Evangelischen Kirche Lutherischen Bekenntnisses in Brasilien: ${ }^{1}$ sua pesquisa sobre a influência da germanidade mostra indícios de uma aspiração da igreja luterana de se aproximar à sociedade brasileira (ver DREHER, 1978, p. 222-230). ${ }^{2}$ Não obstante, Dreher mantém-se preso aos dois paradigmas historiográficos já citados, pois por um lado seus principais interesses são o desenvolvimento da estrutra e da orientação da Igreja e, por outro, a política da germanidade do Império Alemão após 1886 e 1933, como também as consequências da política da nacionalização brasileira.

A maioria dos trabalhos históricos sobre o protestantismo dos imigrantes alemães mostra acentuado interesse na formação de igrejas no Brasil. Essa perspectiva histórica-institucional leva a que os estudos só notem os imigrantes protestantes quando eles fundam igrejas e se associam a sínodos. No centro da observação estão o pastor e os grêmios de direção da igreja. A falta de agentes professionais é, consequentemente, vista de forma negativa. ${ }^{3} \mathrm{O}$ alemão Ferdinand Schröder, historiador de igrejas e pastor, escreve em seu livro Brasilien und Wittenberg sobre essa primeira fase sem pastores: "Nesse lugar passaram-se 20 anos sem trabalho paroquial, que - como vimos hoje - não se recupera nem em cem anos" (1936, p. 79).

De tudo que aconteceu nesses anos - e aqui quero mostrar alguns exemplos - não é tomado conhecimento, ou tudo é respectivamente desvalorizado. De uma extrema perspectiva histórica-institucional são os trabalhos de Hans-Jürgen Prien, Von den 
deutsch-evangelischen Einwanderergemeinden zur Evangelischen Kirche Lutherischen Bekenntnisses in Brasilien (1989), ${ }^{4}$ e de Enrique Krause, Lutherische Synode in Brasilien. Geschichte und Bekenntnis der Evangelisch-Lutherischen Synode von Santa Catarina, Paraná und anderen Staaten Brasiliens (1993). Lauro Emilio Wirth tenta, em sua dissertação escrita na Universidade de Heidelberg, Protestantismus und Kolonisation in Brasilien. Der evangelische Gemeindeverband in Brasilien; Kontextualität, Ekklesiologie und Institutionalisierung einer deutschen Einwandererkirche in Santa Catarina (1992), dar um primeiro passo no sentido de abranger os fenômenos histórico-sociais em sua caracterização contextual. Seu objetivo principal é distinguir a contextualidade das igrejas dentro do interesse da colonização alemã e das condições socioeconômicas, políticas e culturais do Brasil, além de questionar a contribuição de cada uma para o desenvolvimento das igrejas (WIRTH, 1992, p. 9).

Num segundo grupo de autores, a percepção e a descrição dos protestantes alemães concentram-se quase que exclusivamente ao critério de sua "germanidade". A essa visão etnocêntrica-alemã pertencem quase todos os autores alemães, que aproximadamente desde 1860 se ocuparam com o tema dos conterrâneos emigrantes. A Evangelische Gesellschaft für die protestantischen Deutschen in Amerika (Sociedade Evangélica para os Alemães Protestantes na América) escreveu, em 1885, na sua revista Der deutsche Ansied$\operatorname{ler}(O$ colono alemão $):^{5}$

Todo nosso trabalho é uma coisa do reino de Deus na terra; ele vai oferecer aos conterrâneos espalhados as bênçãos do Evangelho na conservação da cultura e hábitos alemães, na manutenção da união da igreja evangélica alemã e escola. Nós fazemos um trabalho cristão, que ao mesmo tempo tem uma importância nacional, de acordo com a particularidade de cada tarefa.

Era-se da opinião de que, "neste país longe, católico e de pouca luz no espírito, os contemporâneos alemães seriam uma luz, um fermento, o sal da vida e uma fonte abençoada para a honra de Deus e para a benção da nossa igreja e do nosso povo" 6 e defendia-se um "processo de germanização"7 da sociedade brasileira. Não se achava isso difícil, pois se considerava o brasileiro inferior ao alemão. Segundo o julgamento do diplomata suíço Johann Jacob von Tschudi,

[...] os brasileiros são moderados, precisavam de pouca coisa para satisfazer suas necessidades, evitam de um modo geral trabalho cansativo e passam o tempo de preferência com canto, dança e músicas nas vendas... (ou) se deixam levar como camaradas preguiçosos, como parasitas ou moradores independentes nas propriedades (1866, p. 72).

Respectiva ao baixo nível cultural, avaliou-se a religião, no caso, o catolicismo, como "descrença brasileira, superstição brasileira e comédia brasileira sem moral" (WIEDEMANN, 1856, p. 77) - e aqui não faço citação alguma de fonte protestante, mas sim cito um teólogo católico promovido em $\mathrm{Mu}$ nique, Dr. Theodor Wiedemann, que atuou por vários anos como padre em Petrópolis.

O pastor Fritz Bliedner manifesta, em 1929, na Evangelischen Diaspora (Diáspora Evangélica), órgão do Gustav-Adolf-Werk, no mesmo tom, a sua preocupação sobre os imigrantes alemães: " "o que podemos fazer para evitar o perigo de uma perda do germanismo? Esses esforços têm chance de êxi- 
to? E se não têm, o que podemos fazer para salvar pelo menos a confissão evangélica, caso ocorra a abrasileirização?"

Pelo visto, os imigrantes protestantes haviam se aproximado da cultura brasileira, o que foi interpretado na Alemanha como uma completa selvageria. Nesse sentido, a revista Der deutsche Ansiedler reclama, também, da "progressiva abrasileirização". ${ }^{9}$ Respectivamente, a tarefa das obras alemãs deveria ser a "de encontrar meios e caminhos de fazer novamente dos colonos abrasileirados colonos alemães." ${ }^{10}$ Ocorreu assim o que, segundo o teólogo católico Theodor Wiedemann, se esperava do emigrante alemão: que "ele deixasse seus hábitos e costumes, para que ele se tornasse como o brasileiro o queria, isto é, animalesco e com isso apropriado a substituir o africano preto" (1856, p. 76).

Exatamente nesse ponto se encontra meu interesse de pesquisa.

\section{Abrasileirização como aculturação: a visão histórica-antropológica}

O discurso da abrasileirização deixou-me curioso: eu quis saber o que se esconde detrás desse conceito. Minha suposição foi que o que devia ser combatido como abrasileirização nada mais era do que a adaptação normal e necessária dos migrantes à nova sociedade. Com meu estudo, quis fazer uma mudança radical de perspectiva: eu não quis mais observar os imigrantes partindo da sua germanidade. Meu interesse de pesquisa focou totalmente no "lado brasileiro" da vida dos imigrantes. Isso significa que tive que analisar o que a Historiografia da Igreja deixou de olhar ou desvalorizou.
De um modo geral, percorro o caminho contrário ao de Martin Dreher e procuro analisar todos os indícios nos quais se apresentam aspectos de abrasileirização dos protestantes de origem alemã (ver DREHER, 1978 , p. 81,226 ). Para isso, retomo várias pistas, que aparecem no trabalho de Dreher sem serem pormenorizadas. Com isso, obrigatoriamente, os protestantes do Brasil central no século XIX, que foram considerados como os mais abrasileirados, se tornaram meu campo de pesquisa. Meu estudo não se coloca como contradição, mas sim como uma perspectiva complementária em relação ao trabalho pioneiro de Dreher.

Em relação ao método científico, na minha procura da abrasileirização, o conceito de aculturação, que foi desenvolvido na Antropologia de Cultura norte-americana no início da década de 1930,11 ajudou-me bastante. A clássica definição do conceito do ano de 1936 diz:

[...] aculturação compreende todos os fenômenos que se resultam quando grupos de indivíduos com culturas diferentes entram em contato permanente, causando subsequentemente alterações nos padrões culturais originais de um ou ambos os grupos (REDFIELD, LINTON, HERSKOVITS, 1936, p. 149).

De acordo com a definição acima, entende-se, sob o conceito de aculturação, todos os fenômenos de transição cultural, que resultam do permanente e direto contato de dois grupos, pertencentes a culturas diferentes. Aculturação não foi definida como transição cultural de um só grupo - no sentido de uma assimilação ou integração -, mas sim como um acontecimento recíproco, que altera o modelo de dois grupos. Nesse caso, 
a aculturação (1) não só acontece de maneira espontânea, ela (2) não precisa se manifestar da mesma forma em todos os membros de um grupo. (3) Aculturação é um processo seletivo, que não atinge todos elementos da cultura, e ela (4) inclui o perigo de desintegração e pode (5) levar ao contrário, isto é, a uma recusa da cultura a ser absorvida, caso haja ameaça de uma deculturação. ${ }^{12}$

O conceito de aculturação serve de base a vários estudos da área de Etnologia (Antropologia Social) (ver LINTON, 1963) e pesquisas sobre migração (ver HANDLIN, 1959, e outros). No Brasil, essa teoria tornou-se conhecida por meio do abrangente estudo pioneiro do sociólogo alemão Emílio Willems (1980), porém é pouco aplicada.

No meu trabalho, usei "aculturação" como um conceito neutro, que deveria me ajudar a observar todos os tipos de contato com a cultura sem julgamento prévio. Certamente, pude constatar que aculturação não é um conceito neutro, e sim um conceito positivo: a abrasileirização é o que eu favorizo e apoio. A conclusão do meu trabalho é a seguinte:

Aculturação é um processo, que ocorreu continuamente desde o primeiro dia da imigração. Ela é um fenômeno de relevância para todas as igrejas do tipo do protestantismo de imigração - seja na América Latina, seja em qualquer outro lugar do mundo. Last but not least a intenção desse trabalho é a de dar um impulso a outras pesquisas sobre fenômenos de aculturação dentro da história do cristianismo fora da Europa (SPLIESGART, 2006a, p. 568).

\section{Fatores de aculturação}

O processo de aculturação pode abranger todos os aspectos da vida. Ele tem sempre um contexto e é influenciado por fatores externos - econômicos, políticos e sociais - como também por fatores internos - psicológicos. Fatores diferentes podem favorecer ou impedir os processos de aculturação. Mas fatores que dificultam a aculturação podem, também, levar a mudanças e adaptações, que, por sua vez, podem, dentro de um novo contexto, ser interpretadas como aculturação, se bem que, no caso, como aculturação negativa (ver DEVEREUX, 1984).

A seguir, serão apresentados dois fatores relevantes que levam definitivamente a processos de aculturação: por um lado, o simples fato da emigração, e, por outro lado, as condições políticas e sociais da emigração no Brasil e na Alemanha.

A visão histórico-social: emigração e aculturação

$\mathrm{O}$ fato de as pessoas abandonarem seu país, para emigrarem para um outro continente, causa sempre processos de aculturação. Essa tese deverá ser demostrada no exemplo das experiências de imigrantes alemães em Nova Friburgo e Teófilo Otoni, em três pontos: a) a decisão de emigrar implicita a disposição de uma mudança radical da própria vida (disposição para a aculturação); b) a longa viagem, às vezes arriscada para a própria existência, leva as pessoas a situações de crise, a qual faz que formas antigas de comportamento apareçam obsoletas. A crise em si pode ser entendida como um rito de passagem, que deixa clara a necessidade 
de interagir com coisas novas (crise como "acelerador" da aculturação); c) os desafios no novo lugar de vida obrigam à adaptação a formas de comportamento, que são apropriadas ao novo contexto (pressão de aculturação).

Em $1^{\circ}$ de fevereiro de 1823, Jacob Heringer, Philipp Heringer e Carl Heiderich entregam uma petição à administração pública de Oberstein, na qual pedem uma autorização para emigrarem para o Brasil. $\mathrm{Na}$ petição, consta o seguinte: ${ }^{13}$

Os súditos assinados se decidiram, porque eles não conseguem mais alimentar sua família nesta região. Por isso eles assinaram em Becherbach um contrato com H. Sauerbronn, autorizado pelos Senhores Peter Weil, Peter e Adolph Saueracker, donos da propriedade Almada perto de Ilheos no Brasil, segundo o qual lhes são assegurados 200 alqueires de terras de plantio e livre alojamento, de modo que um futuro melhor se lhes apresente, depois de terem alcançado o lugar determinado. [...]. Eles pedem ao cartório elogiado que lhes conceda a demissão o mais breve possível.

Nesse procedimento burocrático, fica constada, nos registros, a decisão das pessoas nomeadas de deixarem definitivamente seu país. Como motivos, os emigrantes citam: (1) sua precária situação econômica e (2) a perspectiva de uma vida melhor no Brasil - com terra e casa próprias.

As informações sobre o Brasil eram, à época, escassas, pois aqueles emigrantes foram os primeiros a escolheram esse país como alvo da migração. Mas no Brasil já havia grandes proprietários de terra alemães - Saueracker e Weyl -, os quais desejavam estabelecer conterrâneos nas suas propriedades. Para isso, era necessária uma mediação feita por "agentes da imigração", que firmavam contratos com os emigrantes, regulamentando determinadas condições.

Esse contrato previa que cada família receberia um pedaço de terra de 400 alqueires (Quadratbrassen) (cerca de 74 hectares) (Artigo 2), uma casa (Artigo 3), bem como as ferramentas necessárias para o trabalho, além de plantas e sementes para o início da atividade agrária (Artigo 4). Os custos de viagem corriam por conta dos emigrantes (Artigo 8). O governo brasileiro prometia aos colonos alemães isenção de impostos e taxas nos primeiros oito anos (Artigo 1b), dando-lhes, também, a garantia da nacionalidade brasileira (Artigo 1a). De um modo geral, os contratos prometiam "prosperidade e bem-estar" para os emigrantes, assim como uma vida organizada.

Com isso, fica claro que o principal objetivo dos emigrantes era obter prosperidade no Brasil. Os meios para se alcançar a prosperidade consistiam no próprio trabalho na sua propriedade agropecuária. Com base em relatos de viagem e negociações com os agentes de emigração, soube-se que alguns alemães chegaram a conquistar grandes propriedades de terra, que administravam, entre outros, com escravos. Por que também não tentar sua sorte no Brasil e adaptar-se às novas realidades?

Entre a velha e sofrida existência na pátria alemã e a nova vida cheia de perspectivas no Brasil, havia, no entanto, uma viagem difícil e ameaçadora. Inicialmente, os emigrantes precisavam ir para o local do porto e lá subir num veleiro de alto-mar, que os levaria para o Rio de Janeiro.

$\mathrm{O}$ pastor Sauerbronn, que, juntamente com as famílias Heringer e Heiderich, 
encontrava-se entre os emigrantes, escreve numa carta: ${ }^{14}$

Depois de decorrido 18 dias fomos obrigados a chegar com o barco Den Helder de novo no porto citado, com mastro central quebrado, debaixo de terríveis tempestades. O mastro central foi substituído e tivemos que ficar 28 dias. Saindo daqui eram necessários 12 dias para se chegar ao Canal da Mancha, onde uma tempestade horrível nos obrigou a desembarcar na Inglaterra, no porto de Couse. Depois de termos ficado 11 dias e termos nos abastecidos com mantimentos, continuamos com a viagem para as Ilhas Canárias. 54 dias tivemos que ficar no mar com ventos desfavoráveis diariamente até a Ilha de Tenerifa, a maior ilha das Canárias. Um dia antes da nossa chegada em St. Cruz, capital da ilha de Tenerifa, um pirata africano nos deteu [sic] que tinha a bordo 100 homens resolutos e 36 canhões.

Quando da chegada ao Rio de Janeiro, não havia passado o pior; os caminhos para o lugar de destino teria de ser percorrido a pé ou sob mulas. Muitos dos imigrantes estavam enfraquecidos por doenças. Um imigrante relembra outras dificuldades durante a viagem: "Após dois dias de viagem, chegávamos à [sic] Santa Clara [...]. Nós, os recém-chegados, sentíamos o ânimo desfalecer a cada instante. $\mathrm{O}$ prato de feijão carunchado com farinha, que nos era servido todos o dias, prenunciava o que nos aguardava daqui por diante" (Memórias... In: ROTHE, 1956, p. 52).

Outro imigrante relata sobre a acomodação:

Em parte, fomos alojados na assim chamada "caserna", que, ao mesmo tempo, era a cadeia pública. $\mathrm{O}$ resto foi encaminhado a uma grande casa, ainda inacabada. [...].
Isso significava que deveríamos ter paciência, e cada qual devia resignadamente erigir para si, um provisório quartinho de barro, bambú e cipós, e ali aguardar a solução do problema. Quem visse aquele aglomerado de acampamentos diria talvez, que estava aí um bando de ciganos (Memórias... In: ROTHE, 1956, p. 52).

Resumindo, a viagem tornara-se uma experiência limite, na qual a própria existência estava ameaçada. Muitos dos antigos valores morais dos que estavam a bordo ficaram abalados com essa situação. No final - assim julga a historiadora brasileira Cléia Schiavo Weyrauch - "o simples fato estar vivo era já por si só um acontecimento" para os recém chegados (1997, p. 115). Poder-se-ia, também, descrever a viagem como um "rito de passagem": os imigrantes não eram os mesmos de antes. A crise da viagem tinha questionado a vida anterior e deixado as pessoas preparadas para o novo. Mas o que esperava os recém-chegados na nova pátria?

Os imigrantes tiveram de constatar, em breve, que o que lhes fora prometido no contrato estava cheio de armadilhas. As famílias Heringer e Heiderich, por exemplo, que foram estabelecidas em Nova Friburgo, receberam pedaços de terra cheios de morros, que estavam longe de qualquer ligação a tráfego - e isso acontecia com a maioria do seu grupo. A experiência fundamental dos primeiros anos dessas pessoas no Brasil foi completamente marcada pela luta pela sobrevivência. O imigrante Bruno Marx, de Teófilo Otoni, descreve o sentimento da seguinte forma:

Designava-se-lhes uma porção de mata à beira-rio, e depois, que se houvessem para sustentar os seus familiares. 
Antes da alimentação, era preciso cuidar do abrigo! E tinham de dar-se por satisfeitos com uma choupana provisória de ripas de palmeira e folhagem, erguida numa clareira da mata virgem! (MARX apud ROTHE, 1956, p. 47).

Além disso, havia ameaças, que eram completamente desconhecidas na Alemanha, como escreve Franz Schaper, também de Teófilo Otoni:

Essas choças ofereciam pouca segurança contra serpentes, feras ou indígenas. Estes últimos faziam frequentes saques, e nós, para não sermos trucidados, tínhamos de assistir tudo com boa cara!

A Companhia fornecia alimentos, que eram distribuídos por um certo Besenstein. Ele porém desviava muitas mercadorias, e os infortunados colonos chegavam a padecer fome (MARX apud ROTHE, 1956, p. 42).

Em vez do "futuro melhor", que se esperava alcançar no Brasil, os imigrantes estavam submetidos a perigos, que o conceito choque cultural não descreve de maneira suficiente. Além do mais, a situação era irreversível, pois somente alguns poucos dispunham de meios financeiros para uma viagem de retorno. Para vencer as dificuldades da nova realidade, os jeitos e as práticas aprendidas até então não eram suficientes: tudo isso exercia uma enorme pressão de aculturação nos imigrantes, com consequências em todos os âmbitos da vida, inclusive e esta é a minha tese - no campo da religião.

Em vista das dificuldades dos imigrantes, coloca-se naturalmente a pergunta: por que justamente o Brasil foi a meta deles?
A política de migração no Brasil e na Alemanha

A imigração de protestantes alemães para o Brasil está, também, sob o contexto de condições políticas. Por um lado, o governo brasileiro adotava uma posição amistosa em relação à Alemanha e fomentava sistematicamente a imigração de alemães; por outro, o Império Alemão (desde 1871) via a emigração para o Brasil, em um primeiro momento, de forma negativa. Mais tarde, mudou-se essa disposição e houve outras tendências, que visavam, com a emigração para o Brasil, à ideia de fundar uma colônia exterior. Em todos os casos, encontra-se tal opinião acerca da aculturação dos alemães no Brasil: estes não deveriam de forma alguma adaptar-se aos comportamentos brasileiros, mas sim manter o ser alemão. Essas ideias tiveram efeito nos já atuantes processos de aculturação.

$\mathrm{Na}$ história das famílias imigrantes Heringer, Heiderich e Sauerbronn, sobre as quais foi há pouco relatado, estávamos nos anos de 1823/1824, portanto, no início do Império independente brasileiro. O imperador Dom Pedro I (1822-1831) era casado com Maria Leopoldina da Áustria (1797-1826), uma das filhas de Franz I, da Áustria. Seu filho e sucessor Dom Pedro II governou como imperador brasileiro até a proclamação da República em 1889 (ver BERNECKER, 2000, p. 127-132).

Ambos os imperadores do Brasil - juntamente com a elite do país - orientavam-se pela Europa na sua cultura e política. Por isso, o governo brasileiro esforçava-se, desde o início, de forma planejada, para convencer europeus, e principalmente alemães, a imigrarem, por tais motivos econômicos, políticos e ideológicos: 
a) Com os imigrantes (alemães), queria-se criar uma classe média agrária e artesanal, pensando-se em obter uma modernização do resto da sociedade, como também uma dinamização da economia por meio do lavradio da terra, dos novos métodos de plantio e do know-how técnico-artesanal (BERNECKER, 2000, p. 88).

b) Com o fomento da agricultura na mão de pequenos camponeses familiares, ligavam-se dois motivos políticos: por um lado, buscava-se criar alternativas à economia latifundiária e, assim, apresentar à Inglaterra o interesse em abolir a escravidão. Por outro lado, a coroa brasileira esperava de uma forte classe camponesa apoio leal para a sua política - como contrapeso aos grandes latifundiários, que assumiam convicções federalistas.

c) E, não por último, motivos rascistas tinham importância no fomento da imigração europeia e, com isso, da imigração branca, pois os imigrantes alemães "apresentavam desvantagens em relação aos pretos no que diz respeito a conhecimento da língua, da força e do tipo de trabalho" (BARTELT, 1996, p. 298). O recrutamento de imigrantes alemães servia, assim, como um "branqueamento" da população brasileira, com o que se esperava um melhoramento dos hábitos e costumes.

As expectativas do estado brasileiro para com os imigrantes alemães eram, consequentemente, grandes. Por outro lado, motivos religiosos ou confessionais não ti- nham importância no fomento da imigração alemã. Na Alemanha, via-se a emigração para o Brasil de maneira ambígua, principalmente desde a instalação do Império Alemão em 1871. Por um lado, pensava-se em categorias nacionais e europeias e o Brasil atribuia-se às influências dos USA (BRUNN, 1971, p. 14). Por outro lado, depois da vitória sobre a França a consciência nacional alemã subira tanto, que a recusa a tudo que era galês estendeu-se não só à França, mas a todo campo luso-brasileiro e mediterrâneo. O próprio Chanceler do Império (Reichskanzler) Otto von Bismarck tinha pouca compreensão para com os emigrantes, que "sacudiam sua pátria como uma saia velha" (apud BRUNN, 1971, p. 127).

Junto a essas atitudes esquépticas, havia, em contrapartida, fortes grupos de interesses, que propagavam, conscientemente, a emigração para o Brasil (FISCHER, 1992, p. 290f) e perseguiam, assim, objetivos da política colonizadora. Com um organizado "desvio da emigração alemã de massa do Norte para a América do Sul, eles queriam alcançar [...] [a] teutonização" (Teutonisierung) (BERNECKER, 2002) de completos territórios e, dessa forma, fundar uma "Nova-Alemanha na América do Sul". Era-se, aqui também, da opinião de que os alemães emigrantes deveriam manter sua nacionalidade na língua e nos costumes. Então, visavam a evitar que os alemães se assimilassem a outra raça, ou se transformassem em "adubo para os povos"15 (Völkerdünger), pois a adubação pressupõe uma mistura, que deveria ser evitada de qualquer forma. Para a realização ideal desses objetivos, ponderaram-se regiões, que eram povoadas por "raças 
inferiores" ${ }^{16}$ e, assim, a política de expansão colonial concentrou-se muito em breve no Sul do Brasil, onde, no século XIX, encontrava-se a maior parte dos imigrantes, que se identificavam como alemães, segundo um conceito nacional-étnico. Nesse particular, guardava-se a esperança de que as enclaves alemãs poderiam se tornar estados independentes do Brasil.

Um representante da igreja a favor da política expansionista colonial alemã foi o teólogo protestante Friedrich Fabri, que dirigiu por muitos anos a sociedade de missão Rheinische Mission, em Barmen, e que escreveu suas ideias na obra Bedarf Deutschland der Colonien? (1879) (A Alemanha precisa das colônias?). ${ }^{17}$

A tentativa de, por meio de emigrantes alemães, ganhar influência sobre outros países, para assim dominá-los, havia começado no último terço do século XIX e foi linha política oficial no Império Alemão sob Wilhelm II; hoje denomina-se esse princípio como "informal imperialism" (BRUNN, 1971, p. XI). A partir de então, tinha-se uma intensa preocupação com os imigrantes alemães no Brasil e mandava-se assistência a eles da Alemanha. Isso se mostra no apoio às escolas de língua alemã, na ajuda para a construção de uma imprensa alemã e em várias atividades de igrejas, principalmente através das obras protestantes e igrejas regionais (Landeskirchen).

Todas essas iniciativas para o fomento da germanidade no Brasil tiveram efeitos nos protestantes de origem alemã e nos seus processos de aculturação (cf. DREHER, 1978). No entanto, é importante constatar que a "política da germanização" iniciou-se somente por fim do século XIX. Por isso chamo esse processo de "germanização secundária", pois os imigrantes da primeira e segunda ondas de imigração já viviam, há várias dezenas de anos, no Brasil e encontravam-se - aqui eu cito, de propósito, as comunidades do Brasil central - numa troca aberta em relação à sociedade e à cultura brasileiras. A germanização (secundária) impregnou, no entanto, a percepção de toda a imigração alemã para o Brasil de forma decisiva, e isso influenciou, também, a percepção das primeiras correntes de imigrantes, que, nas primeiras décadas, tinham se desenvolvido completamente independentes da política do império alemão.

\section{Aculturação no campo da religião}

$\mathrm{Na}$ historiografia sobre as igrejas de imigração de origem alemã no Brasil, até hoje, o aspecto da germanidade é, segundo a minha análise, enfatizado de forma exagerada. Por isso fiz uma troca de perspectiva e analisei as igrejas protestantes alemãs em Minas Gerais e no Rio de Janeiro não do ponto de vista de sua germanidade, mas sim do de sua brasilianidade. A seguir, quero apresentar alguns exemplos de processos de aculturação no campo da religião e mostrar, com isso, como ocorreram as interações dos protestantes de origem alemã com o ambiente brasileiro.

\section{Relações cotidianas e religiosidade popular}

Para a vida dos imigrantes no Brasil, era imprescindível manter relações políticas e econômicas com a população brasileira. 
Daí para frente, houve vários contatos na vida privada, que incluíam amizades, sociedades e até casamentos, que nos primeiros anos foram casos de exceção (ver SPLIESGART, 2006a, p. 247-286).

A partir disso, houve uma intensa troca no campo da religião (ver SPLIESGART, 2006a, p. 287-332). Tanto na cultura alemã como na cultura brasileira, eram conhecidas e apreciadas práticas de magia na religiosidade popular: benzedeiros e curadores cuidavam, nos dois grupos, dos problemas práticos, de modo que nesse campo também houve pontos de contato e aproximação para uma troca mútua (cf. BAHIA, 2011). O interessante, aqui, é que cada grupo atribuía ao curandeiro do outro grupo uma competência maior. Quando o respectivo curandeiro chegava aos seus limites, procurava-se o curandeiro do outro grupo (BAHIA, 2011, p. 345). Dessa forma, surgiu nesse meio de protestantes de origem alemã uma religiosidade popular protestante.

Iniciativas de base e pastorado leigo

Nas primeiras décadas depois de sua chegada, os imigrantes protestantes não dispunham de uma estrutura de igreja. Apenas em Nova Friburgo havia um pastor, Oswald Sauerbronn, pois ele decidira emigrar juntamente com seus membros paroquiais. Nessa situação, os próprios protestantes começaram a cuidar de seus interesses religiosos (ver SPLIESGART, 2006, p. 201-206). Tais iniciativas da base levaram a que fossem construídos cemitérios e os primeiros templos.

O mais notável é o fato de que os leigos também celebravam enterros, casamen- tos e batizados. Com isso, estabilizou-se uma forma de pastorado de leigos. De Julius Waltenberg, de Juiz de Fora, é relatado que, depois de pronta a escola evangélica, no início de janeiro de 1861, ele "exerceu a dupla função de professor e pastor" e dirigia o culto regularmente todo domingo para os colonos evangélicos (STEHLING, 1979, p. 276). Em Petrópolis, era também um professor local, o Senhor Jacoby, que de 1859 até 1862 tomava conta da igreja. ${ }^{18}$

Com isso, os imigrantes protestantes conseguiram, por um lado, pôr em prática a tradição luterana do pastorado de todos os crentes e, por outro, manter a igreja. Assim eles puderam assegurar a continuidade da sua identidade protestante na nova pátria e, ao mesmo tempo, distanciar-se do ambiente católico. Por outro lado, o desenvolvimento de uma igreja de leigos deveu-se, exclusivamente, à situação aberta no Brasil, como também à falta de pastores ordenados e de estruturas eclesiásticas formais.

\section{Iniciativas ecumênicas}

Dos primeiros anos e décadas, existem vários exemplos de uma prática ecumênica de base, que considero como típica para a situação do Brasil até o fim do século XIX (ver SPLIESGART, 2006b, p. 478-499). Os imigrantes de origem alemã em Petrópolis relatam que protestantes e católicos visitavam-se mutuamente nos cultos. Um motivo para esse fato era que os católicos não tinham padres que soubessem falar alemão e, assim, procuravam igrejas protestantes para ouvir o sermão (REBELO, 1856). 
Em Juiz de Fora, imigrantes católicos e protestantes chegaram a juntar-se para construir uma "capela de oração" e - com o apoio de professores - celebrar lá, alternadamente, o culto e a missa (STEHLING, 1979, p. 249). Para a questão do cemitério também encontraram uma solução ecumênica. Em 1860, foi inaugurado, pela primeira vez no Brasil, um cemitério, o Cemitério Nossa Senhora da Glória, no qual foram enterrados, juntos, católicos e protestantes (STEHLING, 1979, p. 250).

\section{Protestantes e escravidão}

Enquanto, no caso do Pastor Friedrich Sauerbronn, em Nova Friburgo, somente existem suspeitas de que ele teria interesse na economia de escravos, no caso do Pastor Voges, em Três Forquilhas - RS, e de alguns outros pastores no Sul do Brasil, isso é explicitamente comprovado. Ele possuía doze escravos, com os quais fazia vários negócios, juntamente ao seu sacerdócio (ver WITT, 2002; SPLIESGART, 2006b). Possuir escravos significava ter status na sociedade brasileira daquele tempo, de modo que não é de se admirar que os imigrantes que desejavam alcançar prosperidade ambicionassem por esses símbolos.

No que se refere a Nova Friburgo, pode-se comprovar que vários imigrantes possuíam um e outros, até mais de um escravo (ver SPLIESGART, 2006b, p. 335-387). Isso significa que esses imigrantes não faziam uma economia intensiva de latifúndio, mas que tinham uma ajuda na casa e na lavoura. Os escravos e seus filhos foram batizados protestantes na igreja. Depois da abolição da escravatura, houve, esporadicamente, pares/ casais protestantes de escravos. As relações dos patrões para com os escravos, na maioria, do sexo feminino, eram diversificadas. Provavelmente, os colonos alemães engravidavam com frequência as escravas, o que, na maior parte das vezes, vinha à tona quando as crianças, depois do batismo, tornavam-se livres. No campo religioso, pode-se supor que, por meio dos protestantes afro-brasileiros, chegaram a penetrar nas igrejas influências da religiosidade de origem africana. Se o sincretismo, a mistura de religião africana com cristã, é referida até hoje como um fenômeno exclusivamente do catolicismo latino-americano, a mesma suposição deve valer para o protestantismo.

\section{Missão protestante}

No decorrer do meu trabalho, encontrei uma outra pista interessante e singular: o fato de que as igrejas de imigrantes alemães tomaram iniciativas para a missão da população brasileira católica (SPLIESGART, 2006a, p. 455-477). Por um lado, havia pessoas no meio das igrejas, que, por contatos pessoais, aproximavam-se das comunidades, por casamento ou relações de trabalho, e, por fim, tornavam-se protestantes. Ainda quando as relações não eram voluntárias, como no caso da escravidão, os escravos continuavam leais à crença protestante mesmo depois de sua libertação. Por outro lado, havia alguns pastores que não se dedicavam somente ao trabalho com os protestantes alemães, tendo assumido a missão como sua tarefa. Sabe-se do pastor Leonhard Hollerbach, de Teófilo Otoni, que ele fez viagens missionárias até o Nordeste e que pregava 
para latifundiários brasileiros e seus escravos, engajando-se muito a favor da abolição da escravidão.

Mostra-se, com isso, que as igrejas protestantes alemãs atuavam com suas iniciativas dentro da sociedade brasileira e estavam interagindo com ela. O exemplo da atividade missionária do pastor Hollerbach comprova que o limite clássico entre protestantismo de imigração e protestantismo de missão não pode ser traçado de maneira rigorosa, como parece à primeira vista.

\section{Uma comunidade espirita}

O Brasil é um país que adotou, primeiramente, as formas mais peculiares de religião (da África e da Europa) e, depois, modificou-as rapidamente, formando com os diferentes elementos novas concepções de religião. Assim, das religiões locais dos escravos africanos, que pertenciam a variados grupos culturais, surgiu a religião brasileira do Candomblé, que, por sua vez, foi praticada sob o manto do catolicismo e que contribuiu para o surgimento de um catolicismo popular sincretista.

Da Europa vieram para o Brasil, por meio de escritos do francês Alan Kardec, novas ideias do chamado Novo Espiritismo, uma mistura de religião, filosofia e ciência. Aqui, o espiritismo se alastrou rapidamente e tornou-se, como Kardecismo, uma reconhecida e propagada comunidade religiosa. Os protestantes imigrantes em Nova Friburgo também eram extremamente receptivos a essas ideias espiritistas (ver SPLIESGART, 2006a, p. 389-421). Em 1888, um grupo de protestantes fundou o Grupo Espírita São
João Batista, no interior de Nova Friburgo, num lugar chamado Amparo, ao qual, pouco a pouco, todos os protestantes aderiram. Esse grupo acabou tendo a função de igreja popular nessa região.

Com isso, os protestantes imigrantes participaram do processo - típico do Brasil - da formação de uma nova religião sincretista. Eles não foram de maneira alguma os defensores dos princípios da reforma e da ortodoxia luterana, como desejavam os pastores luteranos e as autoridades da igreja.

\section{Abstract}

The history of the protestants of German origin in Brazil is normally discussed along two lines: the process of church-institutionalization and Germanness. The older literature characterized many of these parishes as brazilianized. This is particularly the case in middle Brazil, in the states of Minas Gerais and Rio de Janeiro. My own approach takes the pejorative designation of,brazilianisation' as a starting point in order to shed light on processes of interaction and transformation. From a theoretical perspective, the concept of acculturation can be applied to historical questions in a productive way. Acculturation refers to all phenomena of cultural change, which occur while two groups of persons from different cultures come in contact with one another. In my research on protestant immigrants of German origin in Brazil in the 18th and 19th centuries two reinforcing factors of acculturation could be identified: first, the decision to emigrate and the crisis it caused; second, the political conditions in Germany and Brazil. Particularly in 
the area of religion many instances of acculturation among these German protestants in Brazil could be identified.

Keywords: Immigration. Protestantism. Acculturation.

\section{Resumen}

La historia de los protestantes alemanes en Brasil es tratada normalmente por dos puntos de vista: pela formación de la iglesia o por su germanismo. Muchas de estas comunidades son caracterizadas en la literatura como abrasileiradas. Ese es el caso principalmente en el Brasil Central, o sea, en los estados Minas Gerais y Rio de Janeiro. Mi abordaje tiene como punto de partida el concepto peyorativo de abrasileirização, para investigar los procesos de interacción y transformación que el expresa. En la perspectiva teórica, el concepto de aculturación de la Antropología Social puede ser aplicado de forma productiva para el trabajo histórico. Bajo aculturación son comprendidos todos los fenómenos de modificación cultural, que resultan del contacto entre dos grupos de diferentes culturas originarias. En la investigación de los migrantes protestantes de origen alemana pudieron ser identificados dos factores que acentuaran la aculturación: por un lado la decisión de emigrar y la crises resuelta de esto, por otro lado, las condiciones políticas en Alemania y en Brasil. Especialmente en el campo de la religión pueden ser demostrados varios fenómenos, que comprueban la aculturación de los protestantes en Brasil.

Palabras clave: Inmigración. Protestantismo. Aculturación.

\section{Notas}

1 Em português, DREHER. Martin. Igreja e germanidade: estudo crítico da história de Igreja Evangélica de Confissão Luterana no Brasil. São Leopoldo, 1984.

2 Martin Dreher escreve, respectivamente, que o objetivo principal da sua geração se resume no seguinte lema: "Chega de sermos designados como a igreja de alemães". (1999, p. 70).

3 Respectivamente, as fontes mais importantes são protocolos de reuniões de grêmios da comunidade, como também correspondências entre pastores e direção da igreja.

4 Em português: PRIEN, Hans-Jürgen. Formação da Igreja Evangélica no Brasil: das comunidades teuto-evangélicas de imigrantes até a Igreja Evangélica de Confissão Luterana no Brasil. Petrópolis, 2001.

5 Zum neuen Jahre. Ein Wort der Verständigung über die Aufgaben der "Ev. Gesellschaft" im allgemeinen und die des "Deutschen Ansiedlers" im besonderen. Der deutsche Ansiedler. 23. Jg., Januar 1885, p. 1-5, hier S. 2.

6 DEDEKIND, Max. Das Jahresfest der Evangelischen Gesellschaft für die protestantischen Deutschen in Amerika. Der deutsche Ansiedler. 47. Jg., September 1909, p. 129-134, aqui p. 134.

7 Das Deutschtum im Auslande und die inneren Bedingungen seines nationalen Zusammenhaltes und Verstandes. Der deutsche Ansiedler. 27. Jg., März 1889, p. 20: "Germanisierungsprozeß".

8 BLIEDNER, Fritz. Zur Lage unserer deutschen evangelischen Gemeinden in Brasilien. Die evangelische Diaspora. 11. Jg., Heft 1, Februar 1929, p. 41-47, aqui p. 42.

9 Jung=Deutschland in Brasilien ohne Kirche und Schule. Der deutsche Ansiedler. 34. Jg., Juni 1896, p. 44-46, aqui 44.

10 Jung=Deutschland in Brasilien ohne Kirche und Schule. Der deutsche Ansiedler. 34. Jg., Juni 1896, p. 45.

11 Esse conceito foi utilizado pela primeira vez pelo etnólogo J. W. POWELL. Introduction to the Study of indian Languages. Washington, 1880, p. 46 (veja DUPRONT, 1965, p. 34, observação 2). Willems (1980, p. 20-24) relaciona-se explicitamente aos resultados do grupo do Social Science Research Council. Uma subcomissão do Social Science Research Councils, ao qual pertenciam Robert Redfield, Melville Herskovits e Ralph Linton, desenvolveu por conseguinte a concepção de Aculturação (acculturation).

12 Motivos de fundo foram as experiências e exigências políticas da sociedade norte-americana, que, 
por um lado, hospedou uma grande onda de migrantes e que, por outro, via-se à frente de uma população indígena, que, contra as expectativas, não se integrava ao modelo branco de civilização. Veja, para a história do conceito da aculturação, Heinz (1993, p. 44-51) e Rudolph (1964). Até esse tempo, partia-se, nos EUA, do pressuposto de que todos os grupos culturais - migrantes europeus, índios e afro-americanos - eram absorvidos através da assimilação na cultura anglo-saxônica, quer dizer, desapareceriam sob a renúncia da identidade de origem. A tese da assimilação foi tanto dogma político como convicção fundamental na pesquisa antropológica. Atrás desse ponto de vista estava a convicção inquebrável de que culturas continuariam a evoluir num sentido otimista do progresso, ou seja, que os assim chamados povos primitivos se anexariam espontaneamente à civilização superior.

13 Unterthäniges Gesuch von Jacob Heringer, Philipp Heringer und Carl Heiderich an das Amt Oberstein. 1. Februar 1823. In: HEPP (1987, S. 251-3.4).

14 SAUERBRONN, Friedrich. Brief an Verwandte und Bekannte in Becherbach. 10.9.1824. In: FRANZMANN (1985, p. 247F).

15 O conceito origina-se do historiador Heinrich von Treitschke (veja BRUNN, 1971, p. 117).

${ }^{16}$ Assim é a opinião de Ernst von Halles (veja BRUNN, 1971, p. 120).

17 Teólogo protestante Friedrich Fabri foi um dos representantes mais importantes das ideias colonizadoras na Alemanha. Fabri foi influenciado pela orientação social-crítica conservativa da Inneren Mission, formada na direção de um "imperialismo social", que considerava a migração de massa como "necessidade político-social" (BADE, 1975, p. 30). A dissertação de Klaus Bade, em 1975, Friedrich Fabri und der Imperialismus in der Bismarckzeit, tematiza a importância de Fabri no contexto dos interesses coloniais alemães de forma mais explícita.

18 Festschrift der Deutsch=Evangelischen Gemeinde in Petropolis, 1913, p. 6.

\section{Referências}

BADE, Klaus J. Friedrich Fabri und der Imperialismus in der Bismarckzeit. Revolution - Depression - Expansion. Freiburg: Atlantis, 1975.

BAHIA, Joana. O tiro da bruxa. Identidade, magia e religião na imigração alemã. Rio de Janeiro: Garamond, 2011.

BARTELT, Dawid. "Integration" durch Exklusion und Vernichtung in Brasilien am Ende des 19. Jahrhunderts: die Abschaffung der Sklaverei und das Massaker von Canudos. In: RONNET, Sergio Paulo; BRIESEMEISTER, Dietrich (Orgs.). Brasilien im Umbruch: Akten des Berliner Brasilien-Kolloquiums vom 20.-22.9.95. Frankfurt am Main, 1996. p. 295-301.

BERNECKER, Walther. Siedlungskolonien und Elitenwanderung. Deutsch in Lateinamerika: das 19. Jahrhundert. Matices. Zeitschrift zu Lateinamerika, Spanien und Portugal. n. 15, 1997. Disponível em: http://www.matices. de/15/15ssiedl.htm. Acesso em: 10 jan. 2013.

BERNECKER, Walther; PIETSCHMANN, Horst; ZOLLER, Rüdiger. Eine kleine Geschichte Brasiliens. Frankfurt am Main: Edition Suhrkamp, 2000.

BRUNN, Gerhard. Deutschland und Brasilien (1889-1914). Köln, Wien: Böhlau, 1971. v. 4. (Lateinamerikanische Forschungen).

DEVEREUX, Georges. Antagonistische Akkulturation. In: . (Org.). Ethnopsychoanalyse. Die komplementaristische Methode in den Wissenschaften vom Menschen. p. 204-233. Frankfurt am Main: Suhrkamp, 2. Auflage, 1984 (1978). In Zusammenarbeit mit LOEB, Edwin E. Zuvor herausgegeben in: American Sociological Review, 7, p. 133-147, 1943.

DREHER, Martin. Kirche und Deutschtum in der Entwicklung der Evangelischen Kirche Lutherischen Bekenntnisses in Brasilien. Göttingen: Vandenhoeck \& Ruprecht, 1978. v. 6. (Arbeiten zur kirchlichen Zeitgeschichte Reihe B). 
- Os impasses do germanismo. In: $\mathrm{KOCH}$, Ingelore Starke (Org.). Brasil: Outros 500. Protestantismo e a resistência indigena, negra e popular. São Leopoldo: Ed. Sinodal/COMIN/ IEPG, 1999. p. 54-74.

DUPRONT, Alphonse. De l'acculturation. In: COMITE INTERNATIONAL DES SCIENCES HISTORIQUES (Org.). Rapports I: Grands thèmes. XIIe Congrès International des Sciences Historiques. Vienne, p. 7-36. Horn/Wien: Ferdinand Berger \& Söhne, 1965.

FISCHER, Thomas. Deutsche und schweizerische Massenauswanderung nach Lateinamerika 1819-1945. In: WALDMANN, Peter; REINHARD, Wolfgang (Orgs.). Nord und Süd in Amerika. Gemeinsamkeiten, Gegensätze, europäischer Hintergrund. Freiburg: Rombach, 1992. v. 1, p. 280-304.

FRANZMANN, Rudolf. Bechertaler Auswanderer berichten über Brasilien. Monatshefte für Evangelische Kirchengeschichte des Rheinlandes. v. 34, p. 245-253, 1985.

HANDLIN, Oscar. Boston's Immigrants. A stu$d y$ in acculturation. Cambridge, Massachusetts: The Belknap Press of Harvard University Press, 1959.

HEINZ, Marco. Ethnizität und ethnische Identität. Eine Begriffsgeschichte. Berlin: Holos Verlag, 1993. (Mundus Reihe Ethnologie, v. 72).

HERSKOVITS, Melville J.; REDFIELD, Robert; LINTON, Ralph. Memorandum for the Study of Acculturation. American Anthropologist, v. 38, n. 1, p. 149-152, 1936.

KRAUSE, Henrique. Lutherische Synode in Brasilien. Geschichte und Bekenntnis der Evangelisch-Lutherischen Synode von Santa Catarina, Paraná und anderen Staaten Brasiliens. Erlangen: Verlag der Ev.-Luth. Mission, 1993. (Erlanger Monographien aus Mission und Okumene, v. 10).

LINTON, Ralph (Org.). (1940). Acculturation in Seven American Indian Tribes. Gloucester: Peter Smith, 1963.
PRIEN, Hans-Jürgen. Evangelische Kirchwerdung in Brasilien. Von den deutsch-evangelischen Einwanderergemeinden zur Evangelischen Kirche Lutherischen Bekenntnisses in Brasilien. Gütersloh: Gütersloher Verlagshaus Gerd Mohn, 1989. v. 10. (Die Lutherische Kirche, Geschichte und Gestalten).

RUDOLPH, Wolfgang. Akkulturation und Akkulturationsforschung. Sociologus. Zeitschrift für empirische Soziologie, Sozialpsychologie und ethnologische Forschung, Neue Folge, v. 14, n. 2, p. 97-113, 1964.

SCHRÖDER, Ferdinand. Brasilien und Wittenberg. Ursprung und Gestaltung deutschen evangelischen Kirchentums in Brasilien. Berlin Leipzig: Walter de Gruyter, 1936.

SPLIESGART, Roland. Slaverei, Magie und Synkretismus. Zur Akkulturation deutscher protestantischer Einwanderer in Brasilien. Wiesbaden: Harrassowitz, 2006b. v. 6. (Jahrbuch für Europäische Überseegeschichte). .Verbrasilianerung" und Akkulturation. Deutsche Protestanten im brasilianischen Kaiserreich am Beispiel der Gemeinden in Minas Gerais und Rio de Janeiro (1822-1889). Wiesbaden: Harrassowitz, 2006a. v. 12. (Studien zur Außereuropäischen Christentumsgeschichte).

STEHLING, Luís Jose. Juiz de Fora. A Companhia União e Indústria e os alemães. Juiz de Fora: Funalfa, 1979.

WEYRAUCH, Cleia Schiavo. Pioneiros alemães de Nova Filadélfia. Relato de mulheres. Caxias do Sul: Editora da Universidade de Caxias do Sul, 1997.

WILLEMS, Emílio. (1946). A aculturação dos alemães no Brasil. 2. ed. São Paulo: Ed. Nacional, 1980. (Überarbeitet und Ergänzt).

WIRTH, Lauri. Protestantismus und Kolonisation in Brasilien. Der evangelische Gemeindeverband in Brasilien; Kontextualität, Ekklesiologie und Insitutionalisierung einer deutschen Einwandererkirche in Santa Catarina. Erlangen: Verlag der Ev.-Luth. Mission, 1992, v. 15. (Erlanger Monographien aus Mission und Okumene). 
WITT, Marcos Antonio. Os escravos do Pastor Voges na Colônia de Três Forquilhas. In: DREHER, Martin (Org.). 500 anos de Brasil e Igreja na América Meridional. Porto Alegre: Edições EST, 2002. p. 261-264.

\section{Fonte}

DEUTSCHE EVANGELISCHE GEMEINDE PETRÓPOLIS (Org.). Festschrift der Deutsch=Evangelischen Gemeinde in Petropolis zur Erinnerung an die Einweihung der Kirche am 24. Mai 1863. Petrópolis, 1913.

DER DEUTSCHE ANSIEDLER. Organ der evangelischen Gesellschaft für die protestantischen Deutschen in Amerika und der Berliner Gesellschaft für die deutsche evangelische Mission in Amerika, Barmen, 10, 1882-79, 1941. (antes: Der Ansiedler im Westen. Berlin, Barmen, 1862-1881).

DIE EVANGELISCHE DIASPORA. Zeitschrift des Gustav-Adolf-Vereins, Leipzig, seit 1, 1919.

ERINNERUNGEN eines alten Kolonisten, der als Kind mit seinen Eltern nach Brasilien kam. In: ROTHE, Max (Org.). 100 anos de colonização alemã em Teófilo Otoni Minas Gerais. 100 Jahre deutsche Einwanderung in Teófilo Otoni Minas Gerais. Portugiesische und deutsche Chronik. Ijuí: Empresa Gráfica de Michaelsen e Correio Serrano, 1956. p. 30-34.

FABRI, Friedrich. Bedarf Deutschland der Colonien? Eine politisch-ökonomische Betrachtung. Gotha: Friedrich Andreas Perthes, 1879.

HEPP, Franz Ludwig (Org.). A imigração alemã para Nova Friburgo 1824. Nova Friburgo, 1987. 321 p. (Coleção de material não publicado).

MARX, Bruno. Aus dem Leben der ersten Kolonisten. In: ROTHE, Max (Org.): 100 anos de colonização alemã em Teófilo Otoni Minas Gerais. 100 Jahre deutsche Einwanderung in Teófilo Otoni Minas Gerais. Portugiesische und deutsche Chronik. Ijuí: Empresa Gráfica de Michaelsen e Correio Serrano, 1956. p. 27-30.
REBELO, Jose Maria Jacinto. A Colonia de Petrópolis em 1856. Relatório Anual do Diretor. Petrópolis, 9 mar. 1857.

ROTHE, Max (Org.). 100 anos de colonização alemã em Teófilo Otoni Minas Gerais. 100 Jahre deutsche Einwanderung in Teófilo Otoni Minas Gerais. Portugiesische und deutsche Chronik. Ijuí: Empresa Gráfica de Michaelsen e Correio Serrano, 1956.

SCHAPER, Franz: Erinnerungen aus dem Leben. In: ROTHE, Max (Org.). 100 anos de colonização alemã em Teófilo Otoni Minas Gerais. 100 Jahre deutsche Einwanderung in Teófilo Otoni Minas Gerais. Portugiesische und deutsche Chronik. Ijuí: Empresa Gráfica de Michaelsen e Correio Serrano, 1956. p. 24-26.

TSCHUDI, Johann Jakob von. Reisen durch Südamerika, v. 1-4. Leipzig: F.A. Brockhaus 1866 (v. 1 e 2), 1867 (v. 3), 1868 (v. 4).

WIEDEMANN, Theodor. Die deutsche Kolonie Petropolis in der Provinz Rio de Janeiro. Freising: Franz Datterer, 1856. 